\title{
Article \\ Effect of Ce Content on Properties of Al-Ce-Based Composites by Powder-in-Tube Method
}

\author{
Mairym Vázquez ${ }^{1,2,3} \mathbb{D}$, Oscar Marcelo Suárez ${ }^{1, * \mathbb{D}}$, Michael Thompson ${ }^{3} \mathbb{D}$, Haneul Jang ${ }^{3}$, Na Gong ${ }^{3}$, \\ David Weiss ${ }^{4}$ and Orlando Rios ${ }^{3, *}$
}

1 Nanotechnology Center, University of Puerto Rico-Mayaguez, Mayagüez, PR 00681, USA; mvazque3@vols.utk.edu

2 Oak Ridge National Laboratory, Materials Science and Technology Division, Oak Ridge, TN 37831, USA

3 Department of Materials Science \& Engineering, The University of Tennessee, Knoxville, TN 37996, USA; mthom133@vols.utk.edu (M.T.); hjang5@utk.edu (H.J.); ngong@utk.edu (N.G.)

4 Eck Industries, Inc., 1602 N 8th St., Manitowoc, WI 54220, USA; david.weiss@eckindustries.com

* Correspondence: oscarmarcelo.suarez@upr.edu (O.M.S.); orios1@utk.edu (O.R.)

Citation: Vázquez, M.; Suárez, O.M.; Thompson, M.; Jang, H.; Gong, N.;

Weiss, D.; Rios, O. Effect of Ce

Content on Properties of Al-Ce-Based Composites by Powder-in-Tube

Method. J. Compos. Sci. 2021, 5, 255.

https://doi.org/10.3390/jcs5100255

Academic Editor:

Francesco Tornabene

Received: 20 August 2021

Accepted: 22 September 2021

Published: 25 September 2021

Publisher's Note: MDPI stays neutral with regard to jurisdictional claims in published maps and institutional affiliations.

Copyright: (c) 2021 by the authors. Licensee MDPI, Basel, Switzerland. This article is an open access article distributed under the terms and conditions of the Creative Commons Attribution (CC BY) license (https:/ / creativecommons.org/licenses/by/ $4.0 /)$.

\begin{abstract}
Al-Ce based alloys have gained recent interest and have proven to have excellent strength without heat treatment and high thermal stability. Challenges with the production of Al-Ce samples from elemental powders arise due to the elemental material before alloying being susceptible to rapid oxidation. The methodology for making superconductive wire, powder-in-tube, was used as a consolidate $\mathrm{Al}$ and Ce elemental powder, and $\mathrm{Al}-8 \mathrm{wt} \% \mathrm{Ce}-10 \mathrm{wt} \% \mathrm{Mg}$ composite powder into bulk nanostructured material. Powder samples are fabricated in an inert controlled atmosphere, then sealed in a tube to avoid oxidation of powders. Therefore, most of the powder is used without much loss. We used 316 stainless-steel tubes as a sheathing material. For Al-xCe wt \% ( $x=8$ to 14) samples of elemental powder, liquid phase sintering was used and for Al-Ce-Mg powder solid-state sintering. Characterization of the bulk consolidated material after sintering, and before and after heat treatment, was made using optical and Scanning Electron Microscope imaging, Energy Dispersive Spectroscopy, Microhardness and Rockwell Hardness test. We demonstrated that microstructure stability in Al-Ce-based specimens can be retained after thermomechanical processing. Densification was achieved and oxidation of powder was avoided in most samples. In addition, we found that $\mathrm{Fe}$ and $\mathrm{Ni}$ in the sheathing material react with $\mathrm{Al}$ in the process, and Ce concentration modifies the reactivity the sheath.
\end{abstract}

Keywords: aluminum; cerium; Al-Ce-Mg; powder metallurgy; powder-in-tube; powder consolidation; nanostructured materials; aluminum composites

\section{Introduction}

Traditionally, aluminum-based alloys have been one of the most used automotive and aerospace materials. Aluminum is a very attractive material for engineering applications since it is a lightweight metal able to attain high strength levels via heat treatment. Recently, aluminum-cerium-based alloys have been studied as an alternative for structural applications at room and high temperatures [1]. Researchers claim that the entire Al-Ce alloys family (including ternary and quaternary alloys) could retain much of their yield strengths at high temperatures compared to traditional Al alloys, enabling the new alloys for high temperature applications [2]. Accordingly, Al-Ce-Mg alloys should have a good performance and thermal stability at high temperature. Sims et al., reported that if Ce is used as a major alloying element for aluminum (over $10 \mathrm{wt} \%$ ) and the industry remains utilizing $\mathrm{Al}$ at the same consumption level, Ce demand will be 21,772.4 metric ton annually, which will lead to the rare earth (RE) industry lowering cost of production [3]. This circumstance compelled scientists and engineers to develop Al-Ce alloys with a high cerium concentration to raise the demand for this metal and impact the RE industry economy. 
The binary Al-Ce phase diagram has been reevaluated by empirical experimentation and has been corrected several times [4,5]. Recent research placed the Al-Ce eutectic point at $\sim 12 \mathrm{wt} \%$ Ce [6], while previous calculations that located the eutectic point at $17.8 \mathrm{wt} \%$ Ce [7].

Powder metallurgy (PM) has been an important manufacturing process to produce aluminum matrix composites [8]. One technique based on PM is the powder-in-tube (PIT), which has been used for making superconductive tape and wire, to counteract the brittleness of some materials that require a sheath for the wire extrusion process; this also helps prevent oxidation of the final product [9]. PIT method involves filling a tube of a sheath material with the powder of interest in an inert atmosphere, sealing both ends; then, the tube undergoes mechanical or thermomechanical deformation that bonds the powder to form a solid material. Further, the production methodology is convenient when working with powders and volatile material. In addition, variables such as tube material composition, compression pressure, sintering time and temperature, and heat treatment temperature and holding time, can be tailored and scaled up in a production setting.

When oxygen reactions with powders must be avoided, an alternative production methodology should be used. The present research proposes the PIT technique as a production method of an Al-Ce composite by using pure aluminum and cerium elemental powders and using 316 stainless steel tubes as sheath material. Reactive liquid phase sintering was selected for consolidating and bonding the elemental powders and solidstate sintering was selected for powders from gas atomization of homogenous melts. Both composite powders and elemental powders were placed in similar containments and underwent mechanical deformation via PIT. Since the present research requires hot processing, we anticipated a reaction between the very reactive pure $\mathrm{Al}$ and Ce powders with iron $(\mathrm{Fe})$ and nickel $(\mathrm{Ni})$ that are part of the composition of the stainless-steel sheath material [10]. Thus, an opportunity arises to determine whether there is a correlation between Ce level and possible reaction with the sheath material.

\section{Materials and Methods}

Upon the first PIT method was used for making the Al-Ce composite material ranging from $8 \mathrm{wt} \%$ to $14 \mathrm{wt} \%$ cerium. We selected liquid phase sintering because we wanted to make a composite via liquid state reaction starting from $\mathrm{Al}$ and $\mathrm{Ce}$ elemental powder, to form intermetallic reinforcements in the microstructure. Pure elemental powders $(0.044 \mathrm{~mm}$, $99.7 \% \mathrm{Al}, 0.25 \mathrm{~mm}, 99.9 \% \mathrm{Ce}$, Alfa Aesar) where mixed and funneled into a commercially available 316 stainless steel $19 \mathrm{~mm}$ O.D. tube with a pressed-sealed end $(62-72 \mathrm{wt} \% \mathrm{Fe}$, $16-18 \mathrm{wt} \% \mathrm{Cr}, 10-14 \mathrm{wt} \% \mathrm{Ni}, 6 \mathrm{wt} \%$ max others). The tube was prepared with a basic cleaning using ethanol. The procedure was made in a glove box under argon atmosphere. The open end was isolated from oxygen by placing a cap of rubber material, and out of the glove box, this end was sealed by folding in a hydraulic press. Then, the tube was compressed in a 136.07 metric ton hydraulic press. The pressed tube was placed and sealed in a capsule with argon and placed into a furnace for $30 \mathrm{~min}$. Temperature for the liquid phase sintering process was $751{ }^{\circ} \mathrm{C}$ for $8 \% \mathrm{Ce}, 747^{\circ} \mathrm{C}$ for $10 \% \mathrm{Ce}, 741^{\circ} \mathrm{C}$ for $12 \% \mathrm{Ce}$ and $771{ }^{\circ} \mathrm{C}$ for $14 \% \mathrm{Ce}$. The different liquid phase sintering temperatures were selected to be at least $100^{\circ} \mathrm{C}$ over melting temperature of each composition, using the binary Al-Ce phase diagram [6]. Figure A1 in Appendix A shows the tubes after liquid phase sintering and polished samples after discarding the sheathing material. Polishing not only assisted in the microstructure evaluation but also removed any roughness left by the tube inside surface. Some samples were not heat treated (HT) and labeled RT (room temperature), while others were $\mathrm{HT}$ at $200{ }^{\circ} \mathrm{C}$ and $400{ }^{\circ} \mathrm{C}$ for $8 \mathrm{~h}$.

The second methodology included the use of Al-8Ce-10Mg wt \% composite powder made at Eck Industries, Inc. (Manitowoc, WI, USA) by gas atomization. The composition of this alloyed powder does not change during the experiment. All the $\mathrm{Mg}$ was found in solid solution. Solid-state sintering was selected to preserve the nanoscale intermetallics found in the powder. The as-provided powder was sieved; fine powder $(<45 \mu \mathrm{m})$ and 
coarse powder $(>45 \mu \mathrm{m})$ were selected. A third set was made by combining fine and coarse powder in equal weight amounts; this powder size was labeled "mixed 50-50." To fabricate Al-Ce-Mg bulk specimens we continued using the same PIT procedure as the reacted powder. The solid-state sintering process was at $450{ }^{\circ} \mathrm{C}$ for $3 \mathrm{~h}$. and some samples were heat treated at $400{ }^{\circ} \mathrm{C}$ for $24 \mathrm{~h}$. and $72 \mathrm{~h}$. Some specimens (RT) were not heat treated. Appendix A (Figure A2) shows in more detail the experimental flow diagram used in the PIT Al-Ce samples. In addition, the test matrix table of Al-Ce and Al-Ce-Mg is included in the said Appendix A (Tables A1 and A2).

For the elemental powder $200{ }^{\circ} \mathrm{C}$ and $400{ }^{\circ} \mathrm{C}$ were selected as Heat Treatment temperature and for the $\mathrm{Al}-8 \mathrm{Ce}-10 \mathrm{Mg}$ wt $\% 400{ }^{\circ} \mathrm{C}$, to not affect the morphology of the intermetallics and induce only diffusion in the matrix and densification of the PIT samples. It has been reported the thermal stability of Al-Ce and Al-Ce-Mg alloys, also, that Al-Ce alloys undergo minor intermetallics changes when heat treated below $520^{\circ} \mathrm{C}$ for $20 \mathrm{~h} \mathrm{[2].}$

It should be noted that this is not a comparative study of Al-Ce vs. Al-Ce-Mg PIT composites samples. Instead, this research seeks to understand the basic properties of AlCe-based composite materials obtained via PIT and the effects of Ce level in the properties of the resulting composites.

We used Rockwell hardness (HR) tests on the Al-Ce composites and Vickers hardness (HV) tests on the Al-Ce-Mg samples. Since the specimens made from elemental powder were more compositional modulated on a longer scale length scale, HR allows for larger indents, which are more representative of the bulk structure. Microhardness test was carried out with a Buehler Micromet III microhardness tester that applied $1.96 \mathrm{~N}$ for $15 \mathrm{~s}$ $\left(\mathrm{HV}_{0} \cdot 2\right.$ test). Rockwell hardness was measured using a Leco LCR-500 hardness tester with maximum load of $147.1 \mathrm{~N}$ with a 1/6" steel ball indenter (HR15TS test).

The Sartorius density determination kit measured the experimental density of the Al-Ce composite before and after heat treatment.

The samples mounted in epoxy and polished were carbon coated to improve their electrical conductivity for scanning electron microscopy (SEM) and optical imaging observation. SEM imaging and energy dispersive X-ray spectroscopy (EDS), performed at Oak Ridge National Laboratory, allowed quantifying the elemental composition of the specimens. A Siemens ${ }^{\circledR}$ D500 diffractometer with $\mathrm{Cu} \mathrm{K} \alpha$ radiation $(\lambda=0.154178 \mathrm{~nm})$ allowed acquiring the X-ray diffraction (XRD) spectra at the University of Puerto Rico-Mayagüez labs.

\section{Results and Discussion}

\subsection{PIT Reacted Al and Ce Powder}

PIT sample micrographs after sintering show a multiphase microstructure. Boundaries between grains can be easily observed on samples at all Ce levels (Figure 1). Dark phases (labeled 1) in the samples are apparent and large $(>50 \mu \mathrm{m})$ in some areas. However, intermediate atomic mass phase (in grey contrast) of irregular shape (labeled 2) are across grain boundaries, whereas needle-like phases (labeled 3) are present in the samples ranging from 8 to $12 \mathrm{Ce}$ wt \%, but not in the hypereutectic composition (i.e., 14 wt \% Ce). As expected, there is a significant difference between the microstructure of the hypoeutectic and hypereutectic Al-14Ce wt \% samples. 


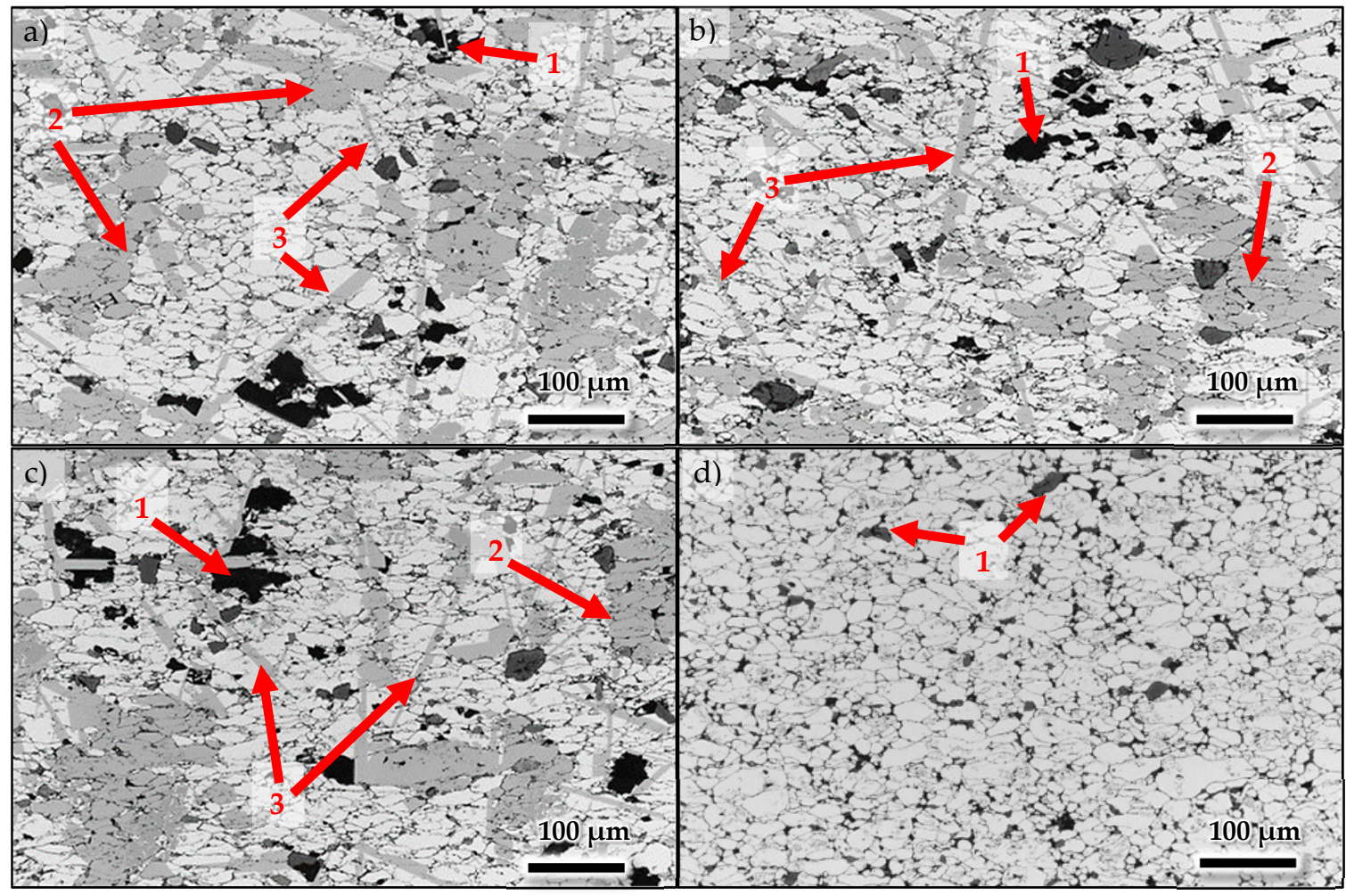

Figure 1. Microstructure of PIT Al-xCe wt \%: $x=(\mathbf{a})$ 8, (b) 10, (c) 12 and (d) 14 .

Upon further investigation, we completed an SEM micrograph analysis on hypoeutectic Ce 8 wt \% and hypereutectic 14 wt \% Ce specimens. Figure 2 provides a side-by-side comparison of the microstructure of Al-8Ce and Al-14Ce wt \% by SEM. These images reveal that at $8 \mathrm{wt} \% \mathrm{Ce}$, the microstructure developed small bright disordered phases (same phases labeled " 1 " in Figure 1) and needle-like one are also present. Moreover, at Ce 14 wt \% only the small bright phases are visible, and the grain boundaries can be easily distinguished.
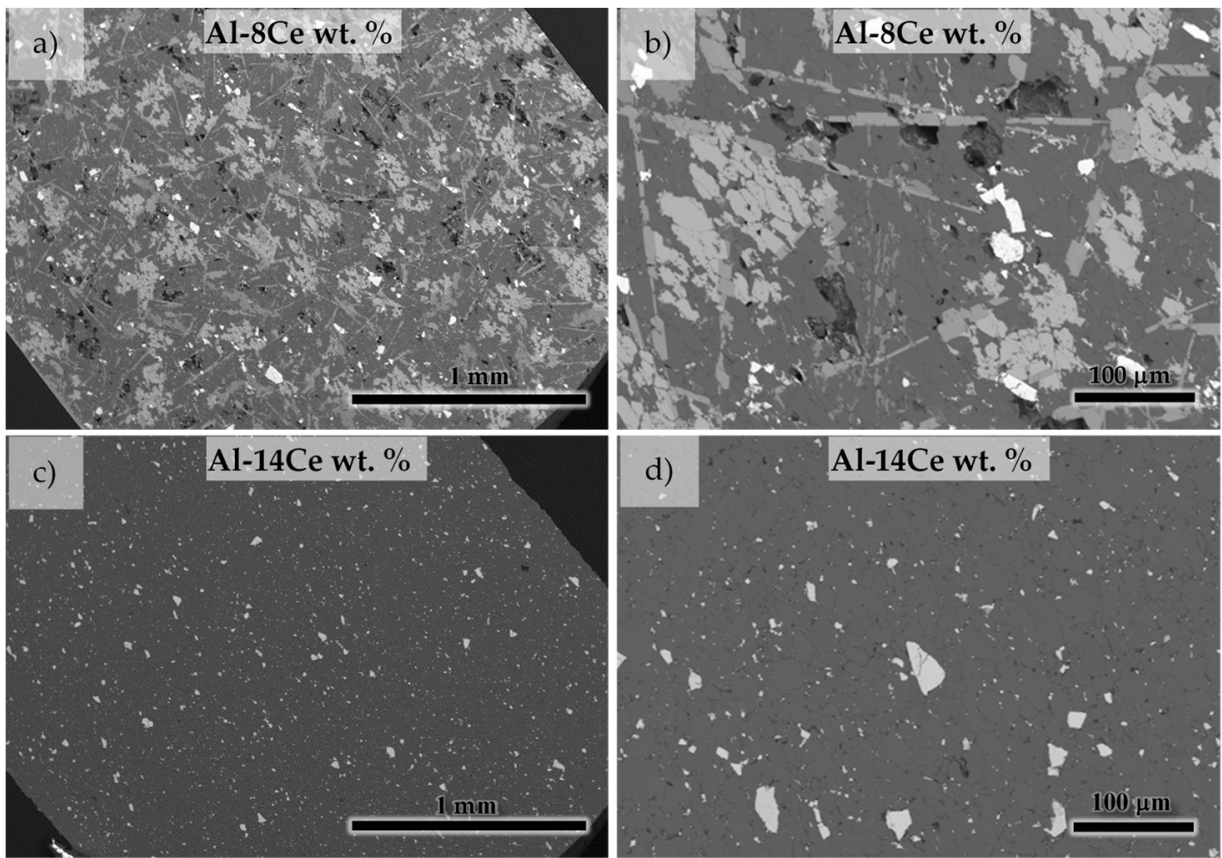

Figure 2. SEM microstructure of PIT (a,b) Al-8Ce wt \% and (c,d) Al-14Ce wt \%. 
XRD patterns for PIT 14 wt \% Ce sample in Figure 3 display diffraction peaks located in almost identical diffraction angles and with similar intensity values of Al FCC (ICSD:187080) and $\mathrm{Al}_{11} \mathrm{Ce}_{3}$ [3]. In contrast, sample containing 8 wt \% Ce present more peaks with a broader one at $44.8^{\circ}(2 \theta)$. This is consistent with $\mathrm{Al} \mathrm{FCC}$ and $\mathrm{Al}_{71} \mathrm{Ni}_{24} \mathrm{Fe}_{5}$ [11]. The pattern in consistent with more disordered phases that are compositionally modulated. Additional peaks are indicative of more phases present in the microstructure, i.e., $\mathrm{Al}_{20} \mathrm{Cr}_{2} \mathrm{Ce}$ (ICSD:236266) and $\mathrm{Fe}_{3} \mathrm{Al}$ [12].

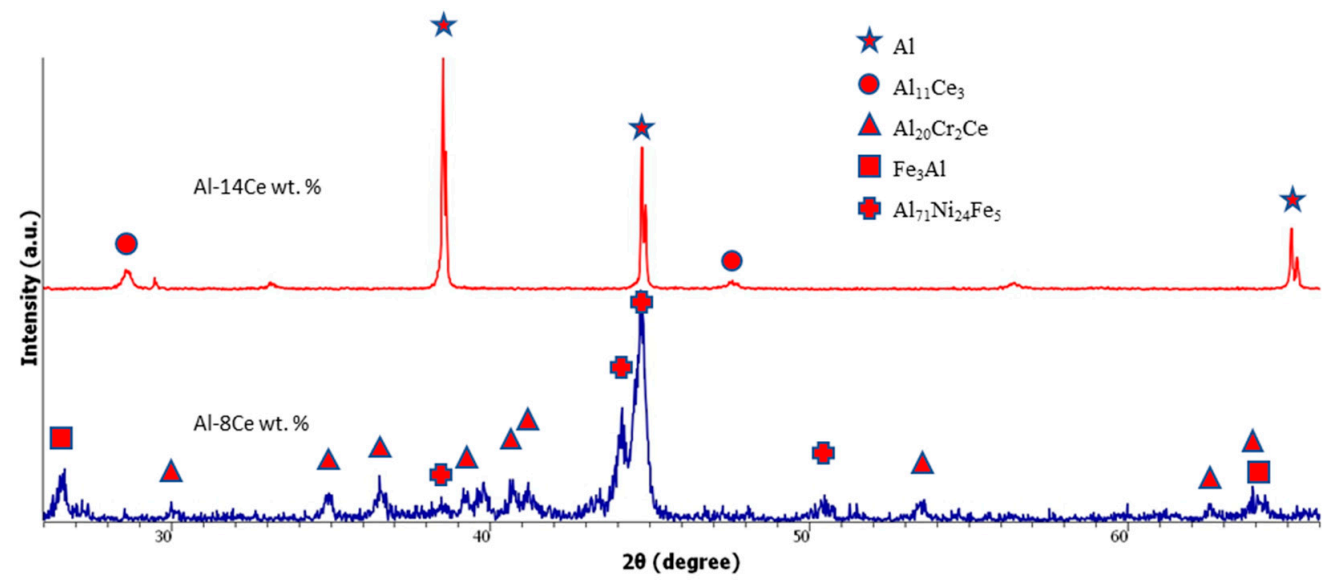

Figure 3. XRD pattern of PIT reacted Al-Ce powder samples.

EDS analysis allowed assessing the elemental composition of the different phases present in the PIT samples microstructures (Table 1). Figure 4a,b show the SEM image displaying the selected EDS analysis points on different phases present in the Al-8Ce wt $\%$ sample and Al-14Ce wt \%, respectively. Figure 4c,e present the EDS spectra for each point. The intermediate atomic mass phase labeled as spectrum 1, contained $\mathrm{Al}(68.25 \%)$, Ce $(18.96 \%), \mathrm{Cr}(12.25 \%)$ and $\mathrm{Ni}(0.54 \%)$. The needle-shape phase labeled as spectrum 2, contained $\mathrm{Al}(68.97 \%), \mathrm{Ni}(15.92 \%)$ and Fe (15.11\%). This Fe-rich needle-like phase is considered a detrimental phase to the properties of aluminum alloys due to local stress concentration leading to very short elongation to failure [13]. EDS identified the bright phase as mostly elemental cerium at $92.7 \%$ for Al-8Ce wt \% sample and $93.3 \%$ for Al-14Ce wt \% (Figure $4 \mathrm{~d}$ ). Cerium is unreacted either in the phase of stirring or in the sintering process.

Using ImageJ software (version I.X.), we calculated the precipitants concentration in the microstructure. The samples of Al-8Ce wt \% contained in average Al-Ce matrix $(66.24 \%)$, intermediate atomic mass phase Al-Ce-Cr $(17.16 \%)$, needle-like phase Al-Fe-Ni $(13.68 \%)$, bright Ce rich phase (1.78\%) and pores (1.14\%) Figure A3. For the Al-14Ce wt $\%$ we calculated average concentration of precipitants as Al-Ce matrix $(96.74 \%)$, Ce rich phase $(2.83 \%)$ and pores $(0.43 \%)$ Figure A4.

Table 1. EDS spectrum elemental composition in wt $\%$.

\begin{tabular}{ccccc}
\hline \multirow{2}{*}{ Element } & \multicolumn{4}{c}{ wt \% } \\
\cline { 2 - 5 } & $\begin{array}{c}\text { Spectrum 1 } \\
\text { Al-8Ce }\end{array}$ & $\begin{array}{c}\text { Spectrum 2 } \\
\text { Al-8Ce }\end{array}$ & $\begin{array}{c}\text { Spectrum 3 } \\
\text { Al-8Ce }\end{array}$ & $\begin{array}{c}\text { Spectrum 3 } \\
\text { Al-14Ce }\end{array}$ \\
\hline $\mathrm{Al}$ & 68.25 & 68.97 & 7.3 & 6.7 \\
$\mathrm{Ce}$ & 18.96 & 0 & 92.7 & 93.3 \\
$\mathrm{Cr}$ & 12.25 & 0 & 0 & 0 \\
$\mathrm{Ni}$ & 0.54 & 15.92 & 0 & 0 \\
$\mathrm{Fe}$ & 0 & 15.11 & 0 & 0 \\
\hline
\end{tabular}



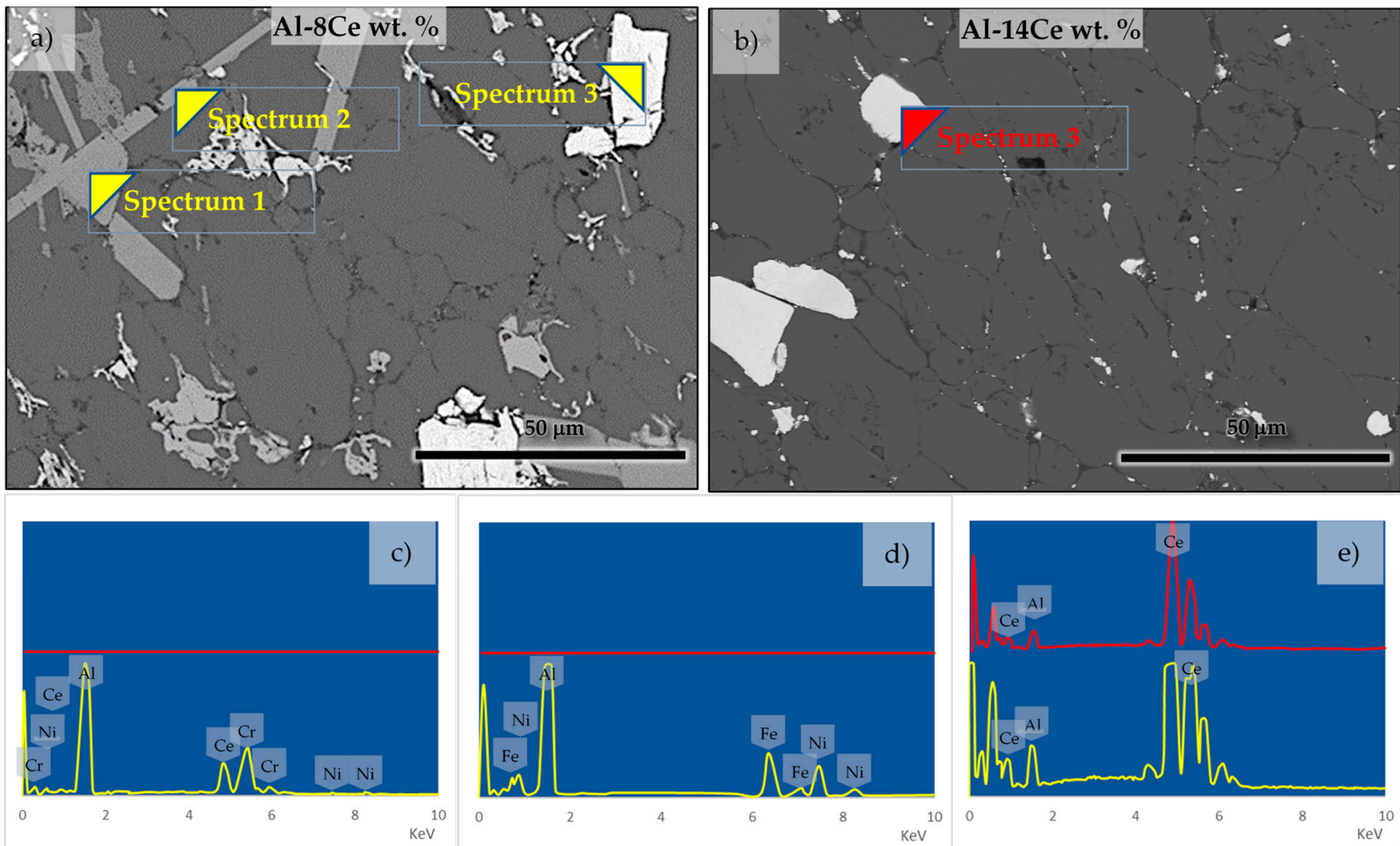

Figure 4. SEM point spectra of (a) Al-8Ce wt \% and (b) Al-14 wt \% processed via PIT. EDS spectrum (c) spectrum 1 (d) spectrum 2 and (e) spectrum 3 of Al-8Ce wt \% (yellow) and Al-14Ce wt \% (red).

The microstructure of the Al-8Ce wt \% samples after $\mathrm{HT}$ at $400{ }^{\circ} \mathrm{C}$ was homogenized and very different from the samples before HT (Figure 5). During HT the Ce intermetallics form into a discrete phase that are finely distributed within domains of $\mathrm{Al}$ solid solution. In addition, the treatment spheroidized the Fe-Ni rich phases, as no needle-like phases are apparent in the microstructure. This finding agrees with previous research that stated that after thermal exposure the Fe-rich phases change from a needle-like shape to a finer spherical morphology [14].



b)
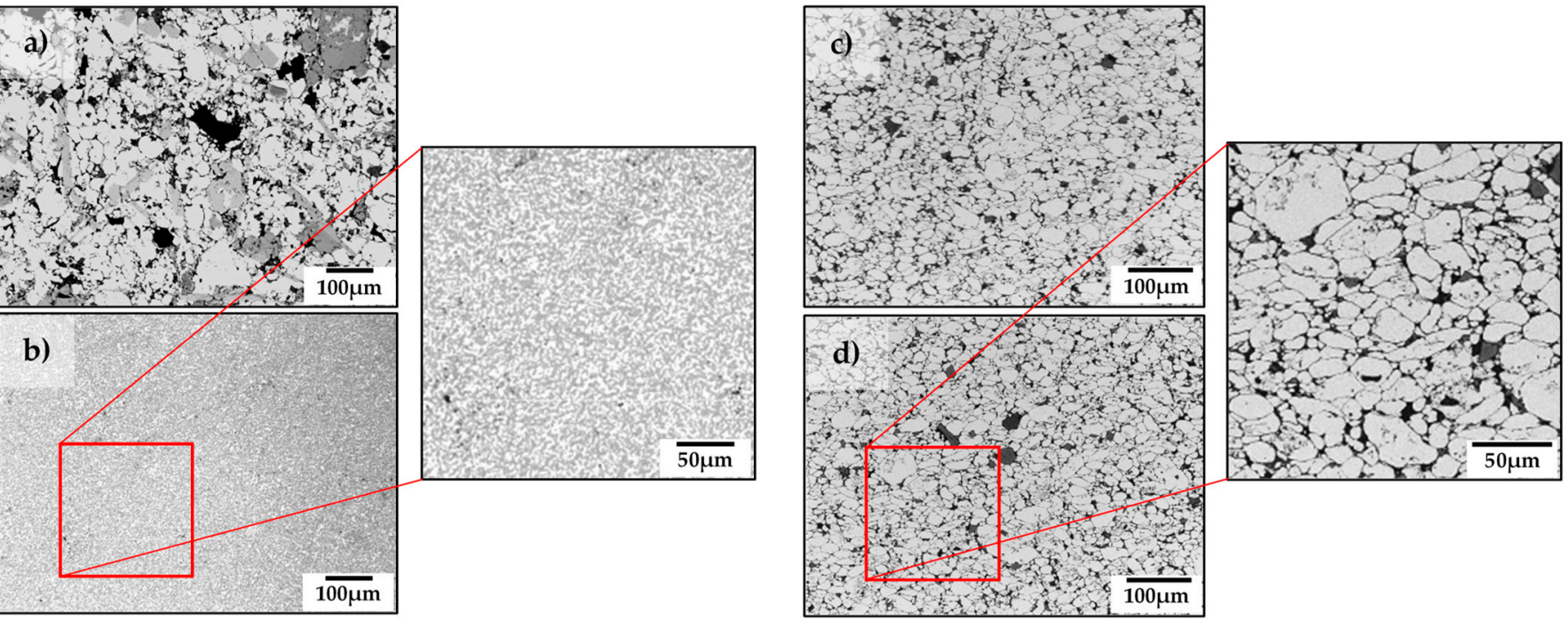

Figure 5. Microstructure comparison of PIT Al-8Ce wt \% sample (a) before and (b) after heat treatment at $400{ }^{\circ} \mathrm{C}$ for $8 \mathrm{~h}$., and PIT Al-14Ce wt \% (c) before and (d) after heat treatment at $400{ }^{\circ} \mathrm{C}$ for $8 \mathrm{~h}$. 
Table 2 shows the Rockwell hardness test (HR15TS) results for the PIT composites before and after HT. Figure 6 shows the results of Rockwell hardness test (HR) for PIT composites before and after HT. Hardness increased in all hypoeutectic samples after both HT conditions. Conversely, at $14 \mathrm{wt} \% \mathrm{Ce}$, there is no significant HR difference for the heattreated composites. This is indicative of a more complete reaction processes between $\mathrm{Al}$ and Ce during the elevated temperature PIT process, that rendered a stable microstructure that is unchanged after $\mathrm{HT}$ at 200 and $400^{\circ} \mathrm{C}$. Considering that the hypoeutectic $\mathrm{Al}-8 \mathrm{Ce}$ wt \% diffractogram revealed less crystallinity after HT, the increment in HR for this samples can be attributed to the formation of new phases and the transformation of the needle-like Fe rich phase after HT. After HT these composites had less porosity, and therefore, higher density. This finding differs from previous literature, which found that the spheroidization of the Fe rich needle-like phase after thermal exposure further negatively affects $\mathrm{HV}$ on Al-1.75Fe-1.25Ni wt \% alloy [14]. This increment difference in our research may be due to Ce content in our samples $(8 \mathrm{wt} \%)$ preventing the phase coarsening by diffusion upon HT. It was addressed that the Fe-Ni rich phases have a detrimental effect in the characteristics of the composite. This is proven when, after heat treatment the hardness for the Al-8Ce $\mathrm{wt} \%$ samples improve significantly, coinciding with the disappearance of the needle-like Fe-Ni rich phases. It will be hard to address, before and after the heat treatment, the impact of the Fe-Ni-Cr, because we don't have Al-8Ce wt \% processed by the same PIT method that does not contain $\mathrm{Fe}, \mathrm{Ni}$ and $\mathrm{Cr}$, thus we cannot make a comparison in hardness.

Table 2. Rockwell hardness (HR 15TS) elemental Al-xCe PIT before and after heat treatment.

\begin{tabular}{|c|c|c|c|c|c|c|c|c|c|c|c|c|}
\hline & \multicolumn{12}{|c|}{ Cerium Content (wt \%) } \\
\hline & \multicolumn{4}{|c|}{ PIT } & \multicolumn{4}{|c|}{$\begin{array}{l}\text { PIT Heat Treated } \\
\left(200^{\circ} \mathrm{C} 8 \mathrm{~h}\right)\end{array}$} & \multicolumn{4}{|c|}{$\begin{array}{l}\text { PIT Heat Treated } \\
\quad\left(400^{\circ} \mathrm{C} 8 \mathrm{~h}\right)\end{array}$} \\
\hline & 8 & 10 & 12 & 14 & 8 & 10 & 12 & 14 & 8 & 10 & 12 & 14 \\
\hline HR & 22.3 & 25.2 & 33.8 & 60.7 & 26.6 & 32.1 & 40.4 & 58.1 & 40.8 & 43.2 & 46.5 & 59.9 \\
\hline s.e. & 2.5 & 1.3 & 0.5 & 3.4 & 0.7 & 0.2 & 0.5 & 0.7 & 0.7 & 0.25 & 0.6 & 1.4 \\
\hline
\end{tabular}

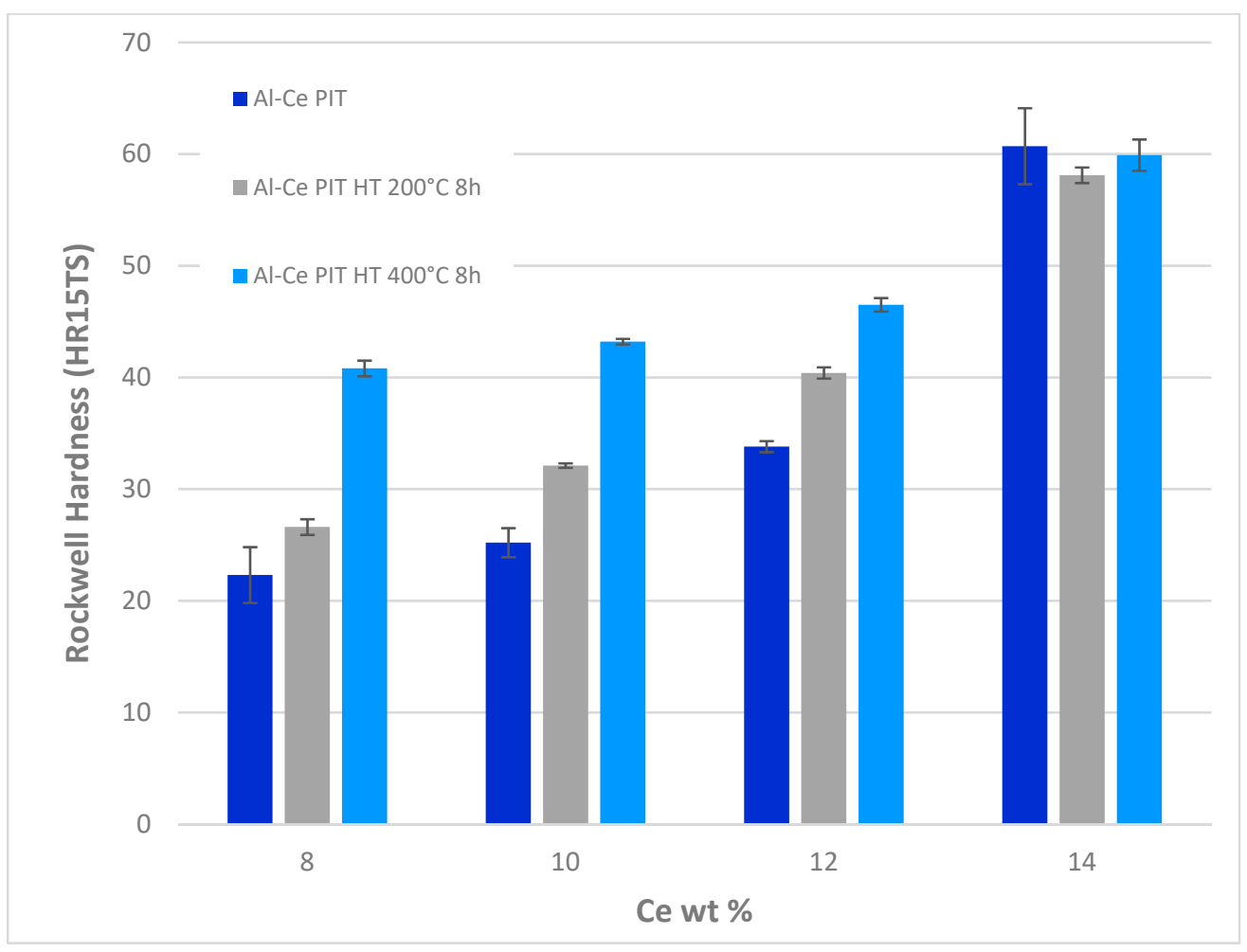

Figure 6. Effects of heat treatment on hardness of $\mathrm{Al}_{\mathrm{x}} \mathrm{Ce}$ PIT reacted powder composites. 
Experimental density $(\rho)$ was measured from all reacted elemental PIT samples (before and after HT). Comparing with the sample before HT, there was a density increase in all heat-treated samples. The smallest difference in $\rho$ increase was in the Al-12Ce wt \% HT at $200{ }^{\circ} \mathrm{C}(+0.17 \%)$ and the largest on the $\mathrm{Al}-14 \mathrm{Ce}$ wt $\% \mathrm{HT}$ at $400{ }^{\circ} \mathrm{C}(+4.31 \%)$. The changes in $\rho$ for the heat-treated samples demonstrates the effect of the HT Table 3.

Table 3. Density Al-xCe via PIT before and after heat treatment.

\begin{tabular}{cccc}
\hline \multicolumn{3}{c}{ Density $\left(\mathbf{g} / \mathbf{c m}^{\mathbf{3}}\right)$} \\
\hline Al-Ce wt \% & PIT & $\begin{array}{c}\text { PIT Heat Treat. } \\
\mathbf{2 0 0}{ }^{\circ} \mathbf{C ~ 8 ~ h ~}\end{array}$ & $\begin{array}{c}\text { PIT Heat Treat. } \\
\mathbf{4 0 0}{ }^{\circ} \mathbf{C ~ 8 ~ h ~}\end{array}$ \\
\hline $8 \%$ & 2.716 & 2.734 & 2.747 \\
$10 \%$ & 2.760 & 2.772 & 2.810 \\
$12 \%$ & 2.812 & 2.817 & 2.839 \\
$14 \%$ & 2.849 & 2.966 & 2.972 \\
\hline
\end{tabular}

The presence of $\mathrm{Ni}$ and Fe rich needle-like phases in the hypoeutectic samples were the result of reaction and diffusion of atoms from the stainless-steel tube used as sheath material. It is known that pure $\mathrm{Al}$ (in our case, elemental $\mathrm{Al}$ powder) is highly reactive with stainless-steel at HT. At $14 \mathrm{wt} \% \mathrm{Ce}$, the solid-state reaction between $\mathrm{Fe}, \mathrm{Ni}$ and Ce takes place at the interface during pressing (at RT) or upon sintering. The high Ce content favors the formation of the phases containing $\mathrm{Fe}$ and $\mathrm{Ni}$ at the tube/sample interface avoiding further $\mathrm{Fe}$ and $\mathrm{Ni}$ reaction with $\mathrm{Al}$ and Ce powder inside the samples (Figure 7).

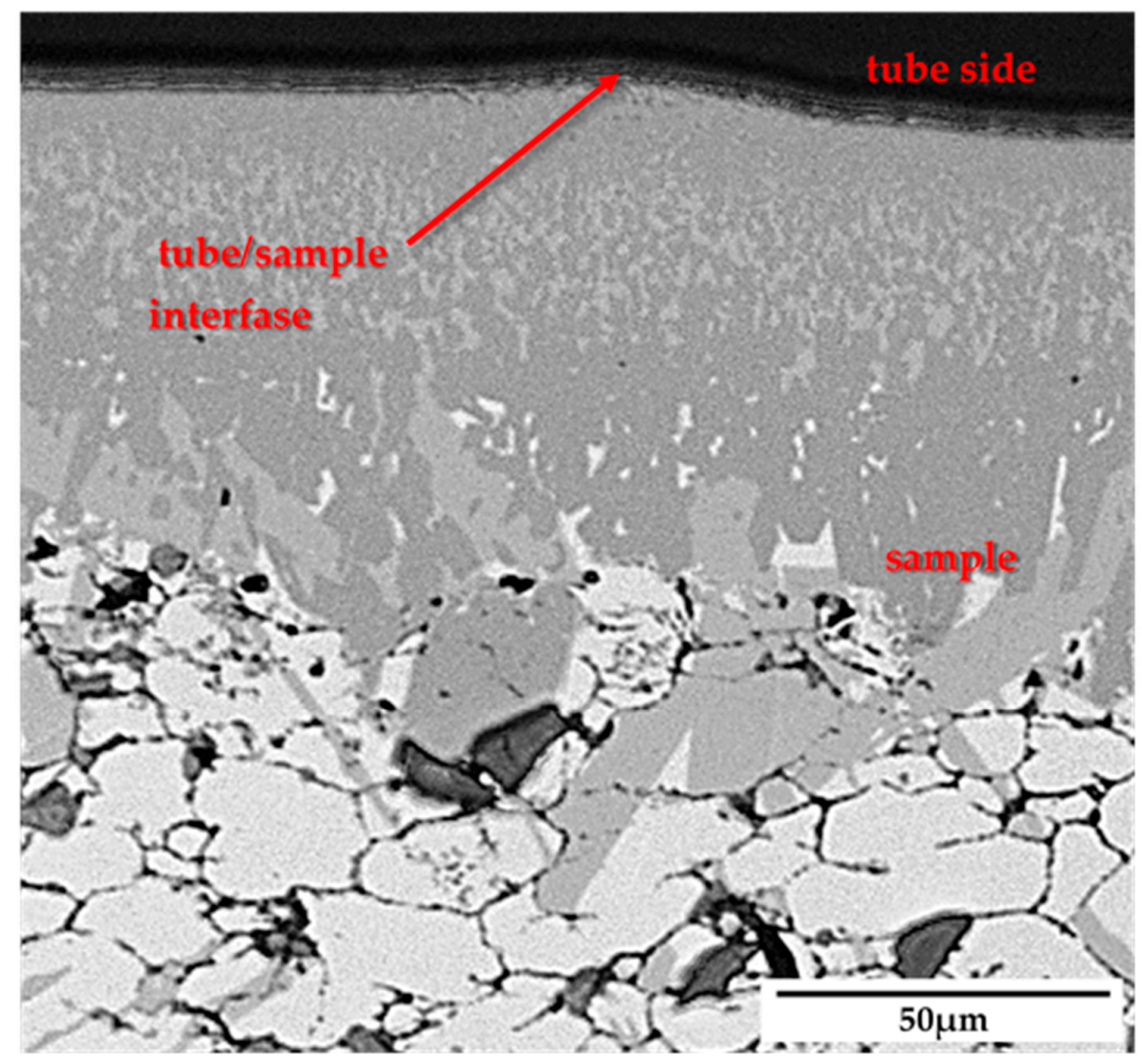

Figure 7. Al-14Ce wt \% via PIT showing the formation of Fe/Ni rich phase at the tube/sample interface after the removal of the stainless-steel tube. 


\subsection{PIT Al-8Ce-10Mg wt \% Composite Powder}

Micrographs of sample of atomized Al-8Ce- $10 \mathrm{Mg}$ wt $\%$ coarse powder before extrusion is shown in Figure 8, where the inset shows in detail the nanoscaled intermetallics in the composite. The microstructure of Al-8Ce- $10 \mathrm{Mg}$ wt $\%$ PIT composites made with all powder sizes, before and after HT is shown in Figure 9. There is no visible difference in microstructure before and after $\mathrm{HT}$ at $400{ }^{\circ} \mathrm{C}$ for 24 and $72 \mathrm{~h}$. Similar results can be observed on samples made of Al-Ce-Mg coarse and mixed 50-50 powder, where the microstructure does not seem to achieve better densification (less porosity) after HT.

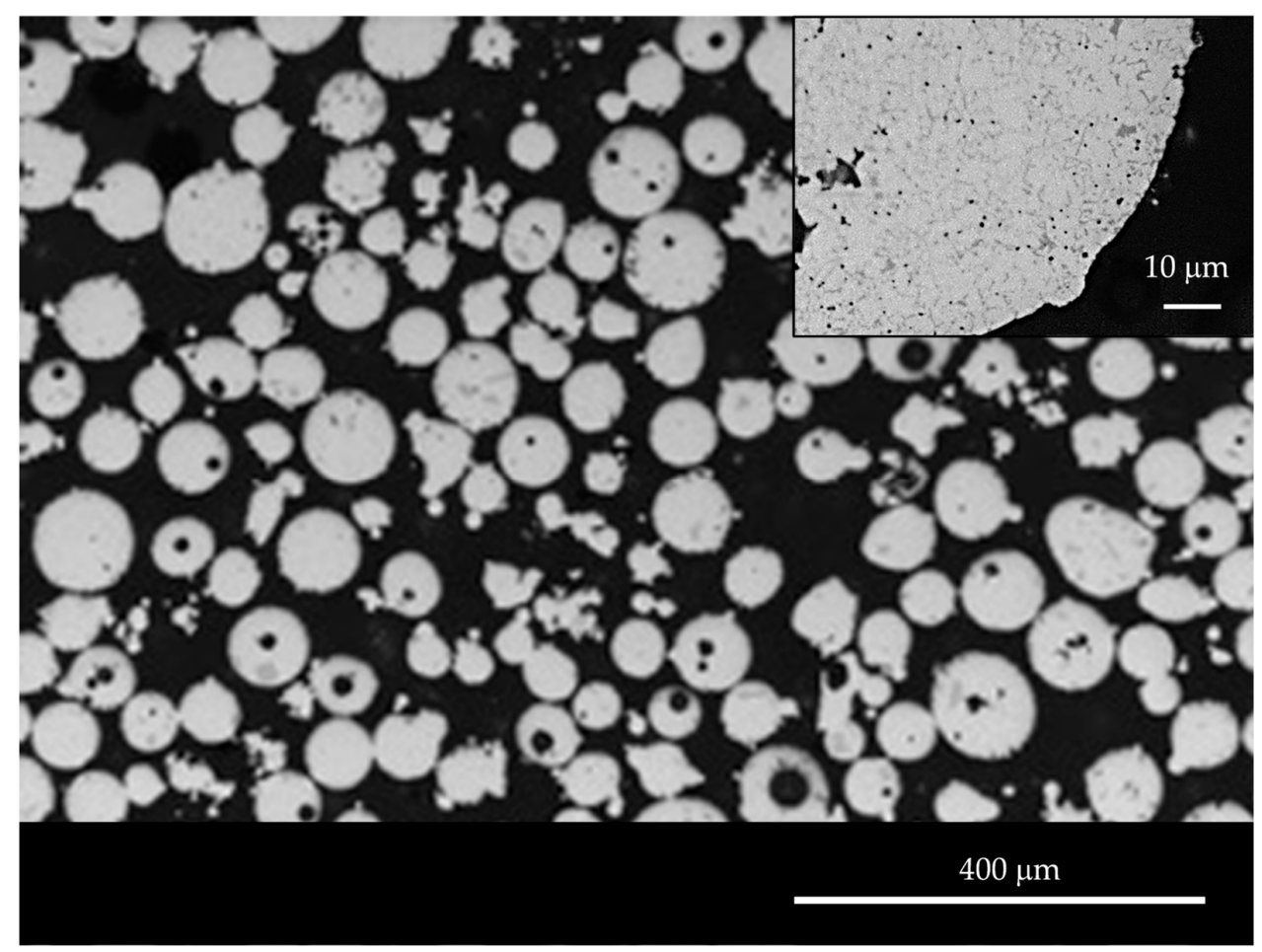

Figure 8. Optical microscopy atomized coarse powder before processing via PIT.

fine


Figure 9. Effects of heat treatment on Al-8Ce-10Mg wt \% fine, mixed 50-50, and coarse powder composites prepared by PIT. 
There is a correlation between HT, holding time and HV results (Figure 10). All powder size samples showed higher HV values after heat treatment for $24 \mathrm{~h}$. This increment was even larger after HT for $72 \mathrm{~h}$. for the fine powder samples. The larger difference in HV increment on the fine and coarse powder samples is due to the preservation of phases in the microstructure and better densification that occurred after HT. Mixed 50-50 samples revealed the best densification of all powder conditions before heat treatment. As a result, the microstructure characteristics were retained, and densification did not change appreciably after HT. Thus, the difference in HV before and after heat treatment is not significant for these mixed 50-50 powder samples.



Figure 10. $\mathrm{HV}_{0.2}$ microhardness in fine, mixed $50-50$ and coarse $\mathrm{Al}-8 \mathrm{Ce}-10 \mathrm{Mg}$ wt $\%$ powders via PIT before and after heat treatment at $400{ }^{\circ} \mathrm{C}$ for $24 \mathrm{~h}$ and $72 \mathrm{~h}$.

\section{Conclusions}

The present research proposes powder-in-tube as an alternative processing method for Al-Ce and Al-8Ce-10Mg wt \% composites starting from reacted and composite powders, respectively. For reacted Al-Ce powders, the PIT process works partially, because the Al-Ce reaction has not completed. Even though distribution of Al-Ce phases occurred, some pure Ce particles were retained in the Al-14Ce wt \% composite. Reacted Al-Ce powder via PIT presented porosity, indicating that higher pressure before sintering may be required for better densification.

Hypoeutectic Al-8Ce wt \% composition show needle-like phases that are confirmed by SEM/EDS analysis to be Fe and Ni-rich phases. On the other hand, the hypereutectic Al-14Ce wt \% composite did not present these phases. We attributed this to the high Ce content causing the formation of stable $\mathrm{Ce}-\mathrm{Fe}$ and $\mathrm{Ce}-\mathrm{Ni}$ intermetallics at the interface between the samples and the stainless-steel sheath. We found that Ce levels affect the Fe reactivity with Al. These intermetallics protected the samples by preventing further reaction between $\mathrm{Al}-\mathrm{Fe}$ and $\mathrm{Al}-\mathrm{Ni}$ inside the material. PIT process is self-limiting: The Ce level needs to be over $14 \mathrm{wt} \%$ to avoid the reaction with the sheathing material.

Al-Ce reacted powder PIT composites at hypoeutectic Ce level presented better densification after heat treatment resulting in higher hardness. For $8 \mathrm{wt} \% \mathrm{Ce}$, this can be attributed to dissolution of the needle-like Fe rich phases. This finding disagrees with the surveyed literature, which reported that the spheroidization of the Fe rich needle-like phase after thermal exposure lowered the $\mathrm{HV}$, e.g., of $\mathrm{Al}-1.75 \mathrm{Fe}-1.25 \mathrm{Ni}$ wt \% alloys. In our research, the difference may be due to the Ce content in the samples preventing the coarsening of the material after HT.

The Al-8Ce-10Mg wt \% composite mixed 50-50 powder samples had better densification, less porosity and higher HV values. In fact, all powder sizes led to steeper HV values after $\mathrm{HT}$, the highest being mixed 50-50 powder samples bearing an $\mathrm{HV}_{0 \cdot 2}=123.8$ after $\mathrm{HT}$ for $72 \mathrm{~h}$. 
Microstructural stability of fine structure in Al-Ce specimens can be retained after thermomechanical processing at elevated temperatures above $700{ }^{\circ} \mathrm{C}$ used in PIT liquid phase sintering and $400{ }^{\circ} \mathrm{C}$ HT to yield a bulk fine structured composite. Nanostructuring Al-Ce-based material is possible and understanding the processing methodology and its effect on the properties of the material is necessary. This study indicates that the PIT processing methodology is highly compatible with Al-Ce based composites due to the stability of fine microstructure during thermomechanical processing and high temperature HT.

Author Contributions: Conceptualization, M.V., O.M.S. and O.R.; methodology, M.V.; investigation, M.V. and M.T.; sample preparation, M.V. and D.W.; writing-original draft preparation, M.V.; writing-review and editing, O.M.S., O.R., H.J. and N.G.; supervision, O.M.S. and O.R.; project administration, O.M.S. and O.R.; funding acquisition, O.M.S. and O.R. All authors have read and agreed to the published version of the manuscript.

Funding: Financial support has been provided by the Transformational Initiative for Graduate Education and Research (TIGER) project through a grant by the US Department of Education, Title V, Part B, Promoting Postbaccalaureate Opportunities for Hispanic Americans (PPOHA) Program (\#P031M140035) and Extramural Research Experience Award (EREA). Laboratory space and equipment has been provided by the Nanotechnology Center for Biomedical, Environmental and Sustainability Applications Phase II. As part of the said Center, this research is based upon work supported by the National Science Foundation under Grant HRD 1345156. Finally, this research was also partially sponsored by the Critical Materials Institute, an Energy Innovation Hub funded by the U.S. Department of Energy (DOE), Office of Energy Efficiency and Renewable Energy, and Eck Industries.

Acknowledgments: Cutting Edge Superconductors, Inc. for materials and laboratory space. Oak Ridge National Laboratory for materials and laboratory space.

Conflicts of Interest: The authors declare no conflict of interest. The funders had no role in the design of the study; in the collection, analyses or interpretation of data; in the writing of the manuscript or in the decision to publish the results.

\section{Appendix A}

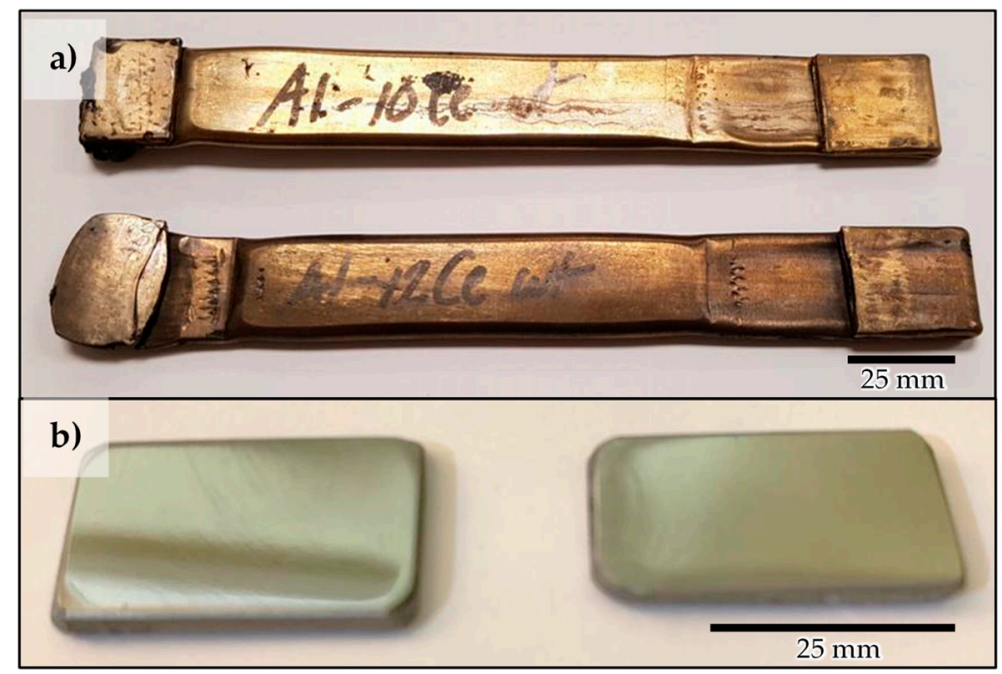

Figure A1. (a) Al-Ce tubes after liquid phase sintering, (b) after removing tube and polishing. 


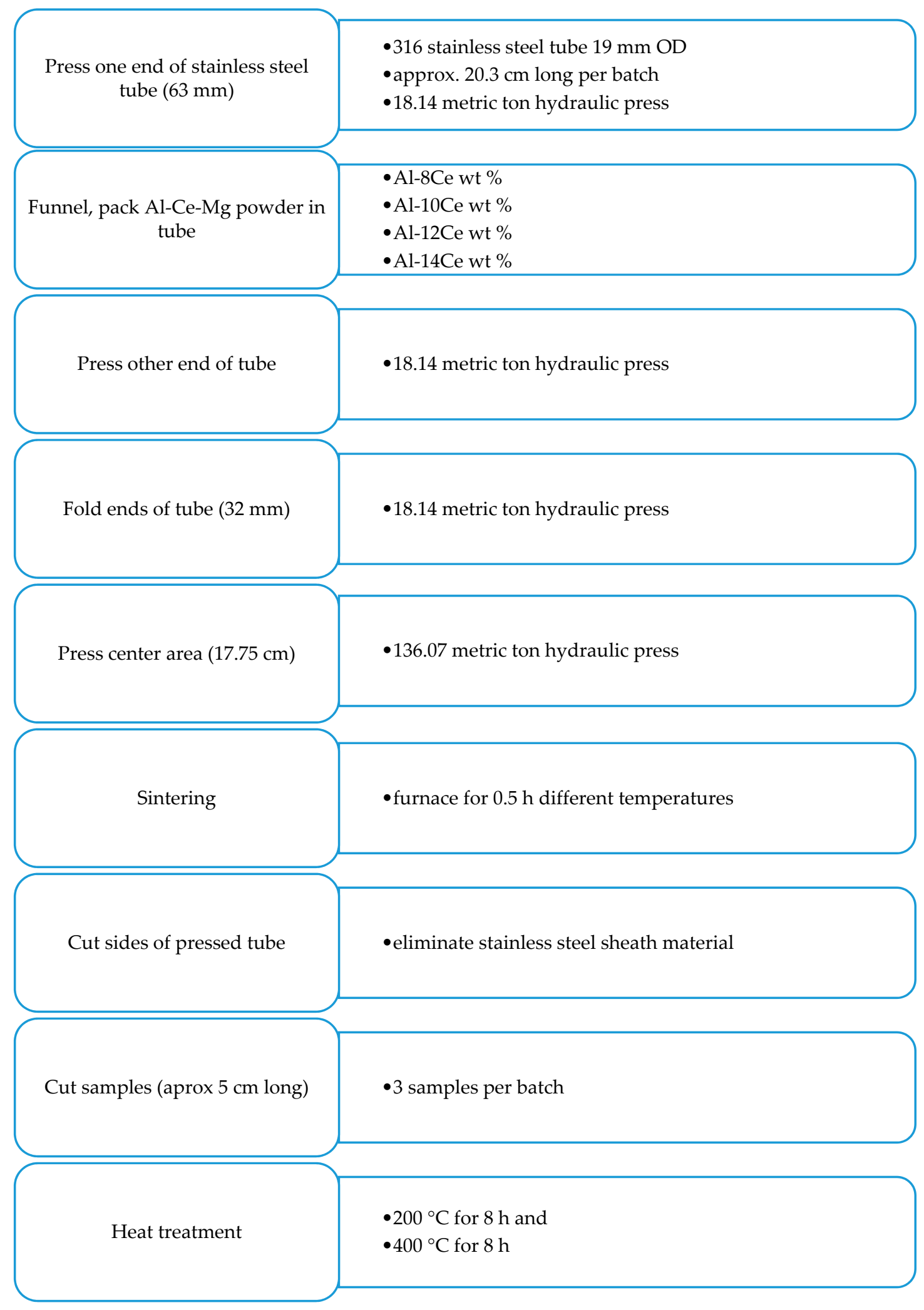

Figure A2. Powder-in-tube process for Al-Ce powder samples. 


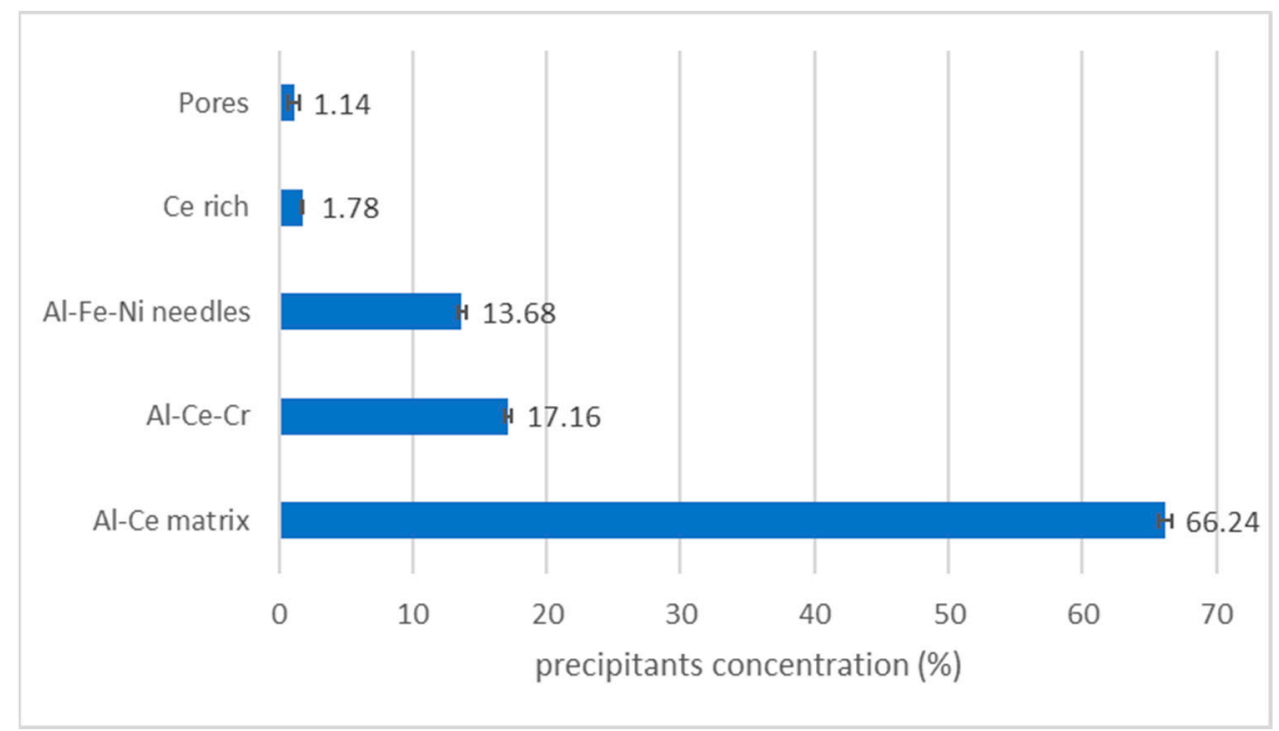

Figure A3. PIT Al-8Ce wt \% precipitants concentration.

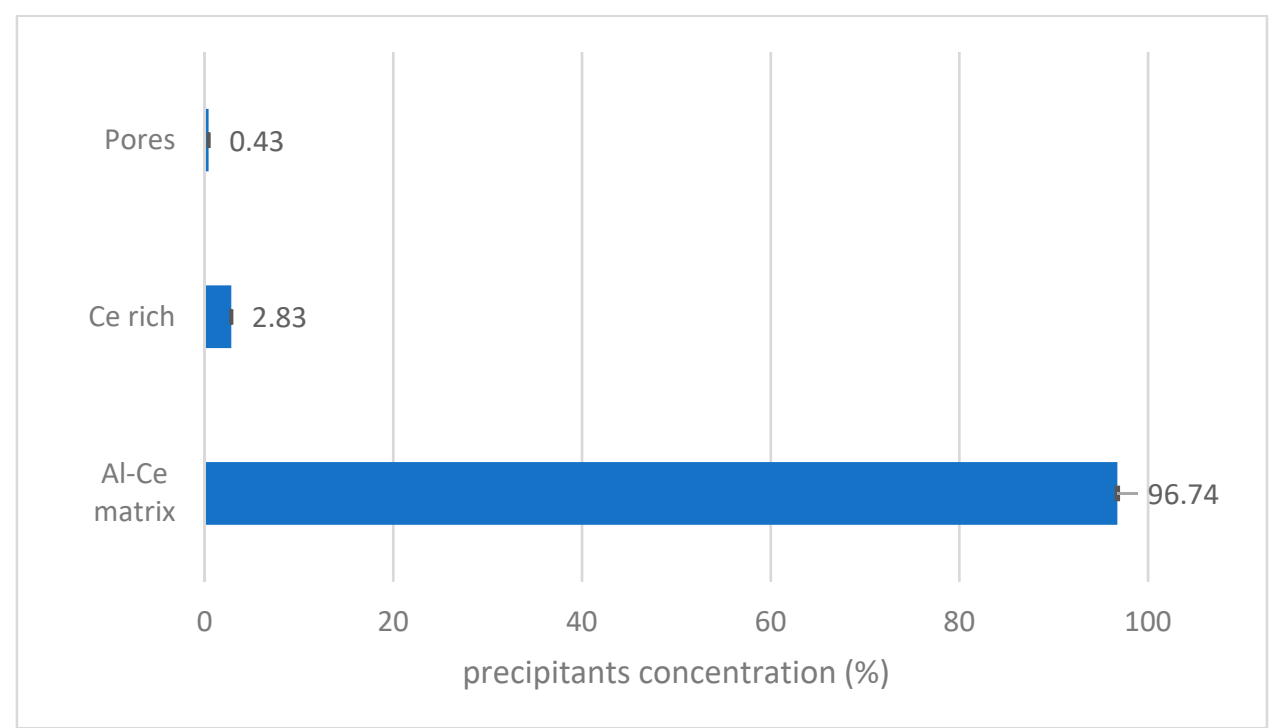

Figure A4. PIT Al-14Ce wt \% precipitants concentration.

Table A1. Test matrix PIT Al-xCe wt \% elemental powder experiments.

\begin{tabular}{|c|c|c|c|c|c|c|}
\hline No. Samples & Composition & Sintering Temp $\left({ }^{\circ} \mathrm{C}\right)$ & Sintering Time (h) & Sample & HT Temp $\left({ }^{\circ} \mathrm{C}\right)$ & HT Time (h) \\
\hline \multirow{4}{*}{4} & \multirow{4}{*}{ Al-8Ce wt \% } & \multirow{4}{*}{751} & \multirow{4}{*}{0.5} & A8 & RT & \\
\hline & & & & B8 & 200 & 8 \\
\hline & & & & C8 & 400 & 8 \\
\hline & & & & A10 & RT & \\
\hline \multirow[t]{3}{*}{3} & \multirow{3}{*}{ Al-10Ce wt \% } & \multirow[t]{3}{*}{747} & \multirow{3}{*}{0.5} & B10 & 200 & 8 \\
\hline & & & & $\mathrm{C} 10$ & 400 & 8 \\
\hline & & & & A12 & RT & \\
\hline \multirow[t]{3}{*}{3} & \multirow[t]{3}{*}{ Al-12Ce wt \% } & \multirow[t]{3}{*}{741} & \multirow[t]{3}{*}{0.5} & B12 & 200 & 8 \\
\hline & & & & C12 & 400 & 8 \\
\hline & & & & A14 & RT & \\
\hline \multirow[t]{2}{*}{3} & \multirow[t]{2}{*}{ Al-14Ce wt \% } & \multirow[t]{2}{*}{771} & \multirow[t]{2}{*}{0.5} & B14 & 200 & 8 \\
\hline & & & & C14 & 400 & 8 \\
\hline
\end{tabular}


Table A2. Test matrix PIT Al-8Ce-10Mg wt \% experiments.

\begin{tabular}{|c|c|c|c|c|c|c|}
\hline No. Samples & Composition & Sintering Temp $\left({ }^{\circ} \mathrm{C}\right)$ & Sintering Time (h) & Sample & $\begin{array}{l}\text { Heat Treatment } \\
\text { Temp }\left({ }^{\circ} \mathrm{C}\right)\end{array}$ & $\begin{array}{l}\text { Heat Treatment } \\
\text { Time (h) }\end{array}$ \\
\hline \multirow{3}{*}{3} & \multirow{3}{*}{$\begin{array}{c}\text { fine powder } \\
\text { Al-8Ce-10Mg wt \% }\end{array}$} & \multirow{3}{*}{450} & \multirow{3}{*}{3} & fine-RT & RT & \\
\hline & & & & fine-HT24h & 400 & 24 \\
\hline & & & & fine-HT72h & 400 & 72 \\
\hline \multirow{3}{*}{3} & \multirow{3}{*}{$\begin{array}{c}\text { mixed 50-50 } \\
\text { Al-8Ce-10Mg wt \% }\end{array}$} & \multirow{3}{*}{450} & \multirow{3}{*}{3} & mixed-RT & RT & \\
\hline & & & & mixed-HT24h & 400 & 24 \\
\hline & & & & mixed-HT72h & 400 & 72 \\
\hline \multirow{3}{*}{3} & \multirow{3}{*}{$\begin{array}{c}\text { coarse } \\
\mathrm{Al}-8 \mathrm{Ce}-10 \mathrm{Mg} \text { wt } \%\end{array}$} & \multirow{3}{*}{450} & \multirow{3}{*}{3} & coarse-RT & RT & \\
\hline & & & & coarse-HT24h & 400 & 24 \\
\hline & & & & coarse-HT72h & 400 & 72 \\
\hline
\end{tabular}

\section{References}

1. Sims, Z.; Rios, O.; McCall, S.; Van Buuren, T.; Ott, R. Characterization of Near Net-Shape Castable Rare Earth Modified Aluminum Alloys for High Temperature Application. In Light Metals; Springer: Cham, Switzerland, 2016; pp. 111-114. [CrossRef]

2. Sims, Z.C.; Rios, O.R.; Weiss, D.; Turchi, P.E.; Perron, A.; Lee, J.R.; Willey, T.M. High performance aluminum-cerium alloys for high-temperature applications. Mater. Horiz. 2017, 4. [CrossRef]

3. Sims, Z.; Weiss, D.; McCall, S.; McGuire, M.; Ott, R.; Geer, T.; Turchi, P. Cerium-based, intermetallic-strengthened aluminum casting alloy: High-volume co-product development. JOM 2016, 68, 1940-1947. [CrossRef]

4. Gao, M.; Ünlü, N.; Shiflet, G. Reassessment of Al-Ce and Al-Nd binary systems supported by critical experiments and firstprinciples energy calculations. Metall. Mater. Trans. A 2005, 3269-3279. [CrossRef]

5. Okamoto, H. Al-Ce (Aluminum-Cerium). J. Phase Equilib. Diffus. 2011, 32, 392. [CrossRef]

6. Cao, Z.; Kong, G.; Che, C.; Wang, Y.; Peng, H. Experimental investigation of eutectic point in Al-rich Al-La, Al-Ce, Al-Pr and Al-Nd systems. J. Rare Earths 2017, 35, 1022-1028. [CrossRef]

7. Okamoto, H. Al-Ce (Aluminum-Cerium). J. Phase Equilib. Diffus. 1998, 19, 396. [CrossRef]

8. Bodukuri, A.K.; Eswaraiah, K.; Rajendar, K.; Sampath, V. Fabrication of Al-SiC-B4C metal matrix composite by powder metallurgy technique and evaluating mechanical properties. Perspect. Sci. 2016, 8, 428-431. [CrossRef]

9. Glowacki, B.A.; Majoros, M.; Vickers, M.; Evetts, J.E.; Shi, Y. Superconductivity of powder-in-tube MgB2 wires. Supercond. Sci. Technol. 2001, 14, 193-199. [CrossRef]

10. Jin, S.; Mavoori, H.; Bower, C.; Van Dover, R. High critical currents in iron-clad superconducting MgB2 wires. Nature 2001, 411, 563-565. [CrossRef] [PubMed]

11. Bindi, L.; Yao, N.; Lin, C.; Hollister, L.; Andronicos, C.; Distler, V.; Effy, M.; Kostin, A.; Kryachko, V.; MacPherson, G.; et al. Decagonite, Al71Ni24Fe5, a quasicrystal with decagonal symmetry from the Khatyrka CV3 carbonaceous chondrite. Am. Miner. 2005, 100, 2340-2343. [CrossRef]

12. Buschow, K.H.J.; Van Engen, P.G.; Jongebreur, R. Magneto-optical properties of metallic ferromagnetic materials. J. Magn. Magn. Mater. 1983, 38, 1. [CrossRef]

13. Shabestari, S.G. The effect of iron and manganese on the formation of intermetallic compounds in aluminum-silicon alloys. Mater. Sci. Eng. A 2004, 383, 289-298. [CrossRef]

14. Bian, Z.; Dai, S.; Wua, L.; Chen, Z.; Wang, M.; Chen, D.; Wang, H. Thermal stability of Al-Fe-Ni alloy at high temperatures. J. Mater. Res. Technol. 2019, 8, 2538-2548. [CrossRef] 